\title{
PLANTS OF GANDHAMARDAN IN MATERNAL CARE: AN ETHNOBOTANICAL APPROACH
}

\author{
SONALIKA DAS, SULAGANA MOHATY, SHEETISWAPNA NAYAK, KALPITA BHATTA*
}

Department of Botany, School of Applied Sciences, Centurion University of Technology and Management, Gajapati, Odisha, India. Email: kalpita.bhatta@cutm.ac.in

Received: 18 April 2021, Revised and Accepted: 28 May 2021

ABSTRACT

Objective: The traditional use of plants in herbal medicine has paved the way for drug discovery. With a view of this, the present study was carried out in Gandhamardan hills which are a rich source of medicinal plants. However, there are copious reports about the plants used in maternal care. Therefore, an attempt has been made to record and document the plants of these hills utilized in maternal care.

Methods: The ethnobotanical information on applications of different plant species to cure diseases and ailments of pregnancy, birth (parturition), and postpartum (puerperium) were documented through personal discussions, interviews with focused groups combined with field visits, voice recordings, and photo documentation.

Results: The study showed that 24 vascular plant species belonging to 24 genera and 22 families have been used in maternal care. Most of the species were herbs (50\%) followed by trees (32.5\%), climbers, and herbs (20\%). It was observed that among all the parts, generally leaves were widely used.

Conclusion: This ethnobotanical study documented the use of plants among the local community. It also revealed that the medicinal plants of the hills are a cheap source of herbal drugs for the rural communities. The information gathered can be used for further scientific investigation to develop new plant-based commercial drugs as they will be safer than synthetic drugs.

Keywords: Gandhamardan, Herbal medicine, Maternal care, Vascular plants.

(C) 2021 The Authors. Published by Innovare Academic Sciences Pvt Ltd. This is an open access article under the CC BY license (http://creativecommons.org/ licenses/by/4.0/) DOI: http://dx.doi.org/10.22159/ajpcr.2021v14i7.41862. Journal homepage: https://innovareacademics.in/journals/index.php/ajpcr

\section{INTRODUCTION}

Herbal treatment has increased significantly during modern times. It has been the oldest treatment which is considered as a precursor of the modern pharmaceutical trade. Plant has therapeutic properties such as wound healing, pain relief, and digestive care which have been widely exploited for disease prevention purpose [1]. The WHO estimates that about half of the population in developing countries depends on alternative or traditional medicines. In general, the plants constitute a major part of this treatment [2]. Pregnancy, delivery, and postpartum are a significant part of matrescence [3]. During this period, women mostly depend on herbal medicines on the assumption that they have fewer side effects, safer, and of natural origin. Maternal care has been an important part of childbirth as it is one of the major concerns due to the high maternal and infant mortality rate in recent times. Hence, we have to focus on these three phases such as prenatal, delivery, and postnatal for maternal care $[4,5]$. During the pregnancy period, women mostly suffer from vomiting, preeclampsia, common cold, and urinary tract infection, heartburn, premature labor, miscarriage, increase in blood flow, abortion, and allergic reactions [5]. Women frequently use herbal medicines to treat all the above-mentioned diseases [6]. However, the depletion of forests and the fast disappearance of the ethnic group have posed a major challenge to document the folk for claims and its authenticity [7]. Therefore, in this study, an attempt has been made to document plants used by local communities of the Gandhamardan hills of Bolangir districts. The hills have huge ethnobotanical potential and have always allured the ethnobotanist [8].

\section{METHODS}

\section{Study area}

Gandhamardan hill is located between $20^{\circ} .52 ' .26^{\prime \prime}$ North latitude and $82^{\circ} .50$ '.34" East longitude on the Odisha Chhattisgarh border near Paikmal on the Bargarh and Bolangir district's borders (Fig. 1). It is a rich source of indigenous medicinal plants. Over 200 Vaidya's or traditional Ayurvedic medicine practitioners are work in this region to collect medicinal plants and treat several diseases. Locals here believe that over 500 species of medicinal plants can be found here. IT shows a remarkable floristic composition in its diversity by a healthy rainfall of $1400 \mathrm{~mm}$ annually by northeastern monsoon. Climate is extreme in this region due to its altitude (1065 $\mathrm{m}$ above MSL) (Fig. 2). Depending on the local climatic and geographical features, the vegetation of Gandhamardan can be divided into two distinct categories between the foothills $(30 \mathrm{~m}$ above MSL) and the plateau (1065 m above MSL): Dry deciduous and semi-evergreen forests. About 912 vascular plant taxa pertaining to 142 families and 556 genera have been documented so far from here [9].

\section{Sampling stagiaries}

The ethnobotanical information on applications of different plant species to cure disease and ailments were documented through personal discussions, interviews with focused groups combined with field visits, voice recordings (VRs), and photo documentation. The traditional knowledge (TKDL) was recorded through semistructured questionnaires using methods such as Participatory Resource Monitoring, Participatory Rural Appraisal (PRA), Focused Group Discussions (FGDs), Personal Interviews (PIs), Key Informants (KIs), and VRs [10] and by consulting TKDL holders/vaidya/hakims/ disharies, etc. Several field visits were conducted to all the two study sites in the year 2019-2020. PIs of each nine KIs and FGDs involving 30 tribal peoples of 12-14 villages, covering the study sites were made to codify the indigenous TKDL of the tribal of Odisha. Structured questions have been developed for interviewing the KIs for gathering information on local plant names, uses, disease to be treated, methods and mode of medicine preparation, etc. The information about the plant mainly focuses on medicinal properties followed by their socioeconomical values. VRs - both audio and video and photo documentation were followed to record the application of the life-sustaining bioresources in all the habitats selected for sampling. Global positioning system readings were taken to identify and map the habitats of both plant 


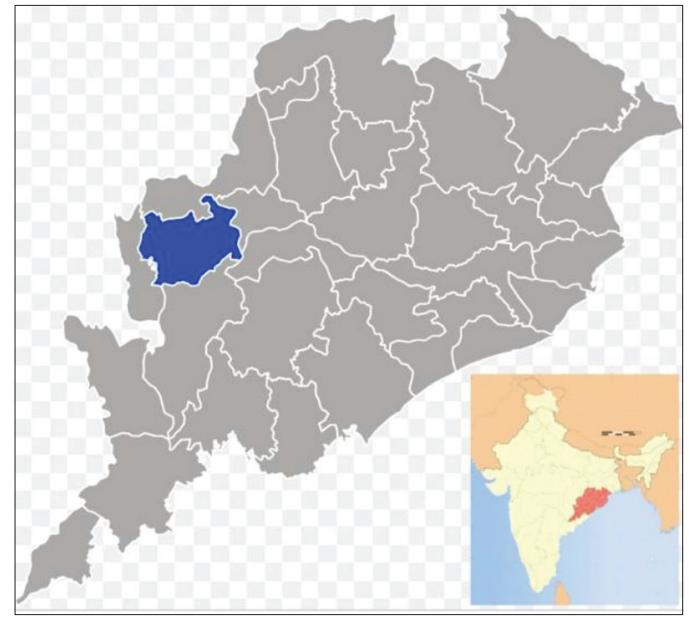

Fig. 1: Map showing Bolangir district in India and Odisha

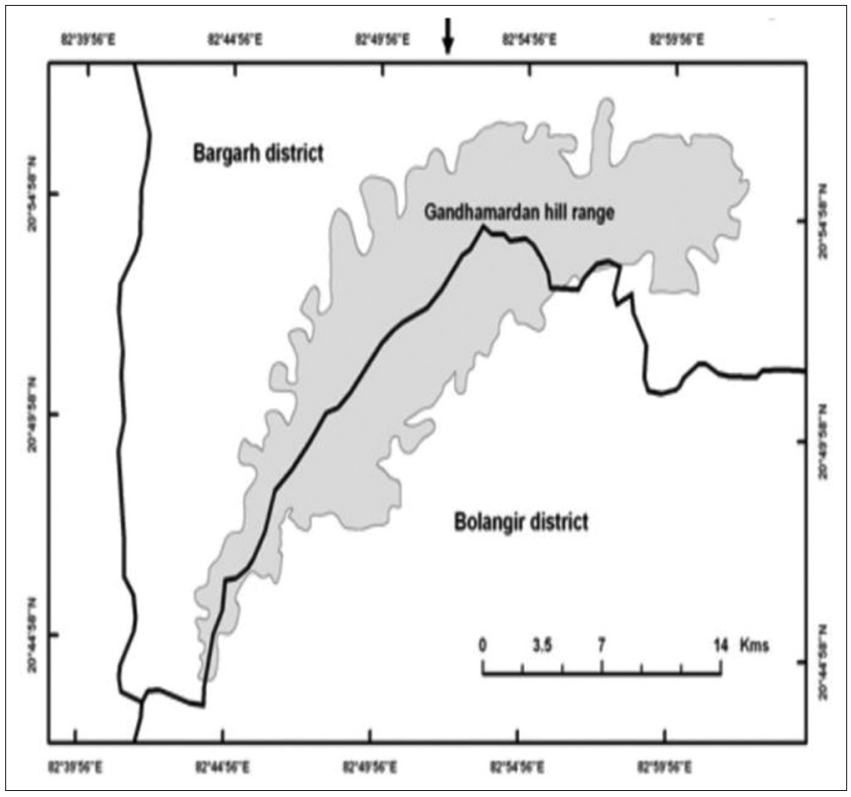

Fig. 2: Map showing Gandhamardan hill species and the Primitive tribal group (PTG) habitats at each site for georeferencing. Collected data were analyzed by taking a comparative study and verified by cross-checking the data during PRA and other observational studies [11].

\section{Preparation of herbarium specimens and identification}

The "Handbook of Field \& Herbarium Methods" by Jain \& amp; Rao, 1977, was followed for preparing the herbarium and the herbarium specimens of the identified plants with accession numbers, date, and place of the collection are submitted to Centurion University of Technology and Management, Bhubaneswar, Odisha [12,13]. Field guides such as Hooker, 1877; Haines, 1921-1925; and Saxena and Bramham, 1989; 1994-1996 were followed for the identification of plant species $[14,15]$.

\section{RESULTS AND DISCUSSION}

A total of 20 informants were interviewed, out of these 12 women and 8 men. That interview was conducted by the team members (three students, guide, and tribal people). A total of 24 therapeutic vascular plant species under 24 genera and 22 families were documented during the study. The medicinal plants have been categorized into different forms depending on their habit. The parts of the plants were used by the people in various forms such as powder, paste, juice, and whole plant. The scientific name of plants used, their local name, habit, their family, and their ethnomedicinal uses were recorded and are given in Table 1.

Fabaceae is the most widely present family as it has been represented by three species as compared with others. The roots were commonly used by the local healers in treating different aliments of the prenatal, delivery, and postnatal periods (Fig. 3). Roots were followed by bark. Roots have a high frequency of use due to the presence of a higher concentration of secondary metabolites than other plant parts $[15,16]$.

Seeds and leaf have the same frequency in usage. In general, the paste form was the most popular method to facilitate the administration purposes than the other mode of utilization which includes infusion, powder, and juice. The paste was well represented by $41.06 \%$ followed by juice (33.03\%), fusion (29.01\%), and powder (12.05\%) (Fig. 4). Herbs were more regular in use and have the highest frequency (50\%) followed by the tree (Fig. 5). It could be presumed that probably herbs contain more bioactive compounds when compared with others $[17,18]$.

For infusion purposes, more commonly honey, rice washed water, or cow's milk were used.

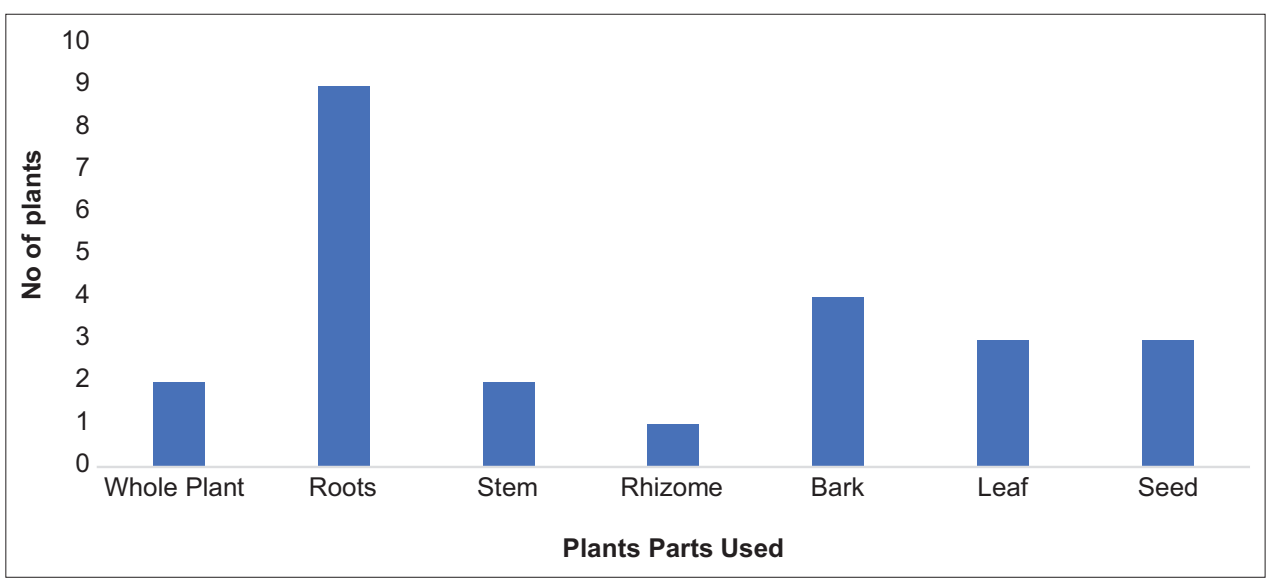

Fig. 3: Plants parts used 
Table 1: Scientific name local name family habit parts used mode of ethnomedicinal use

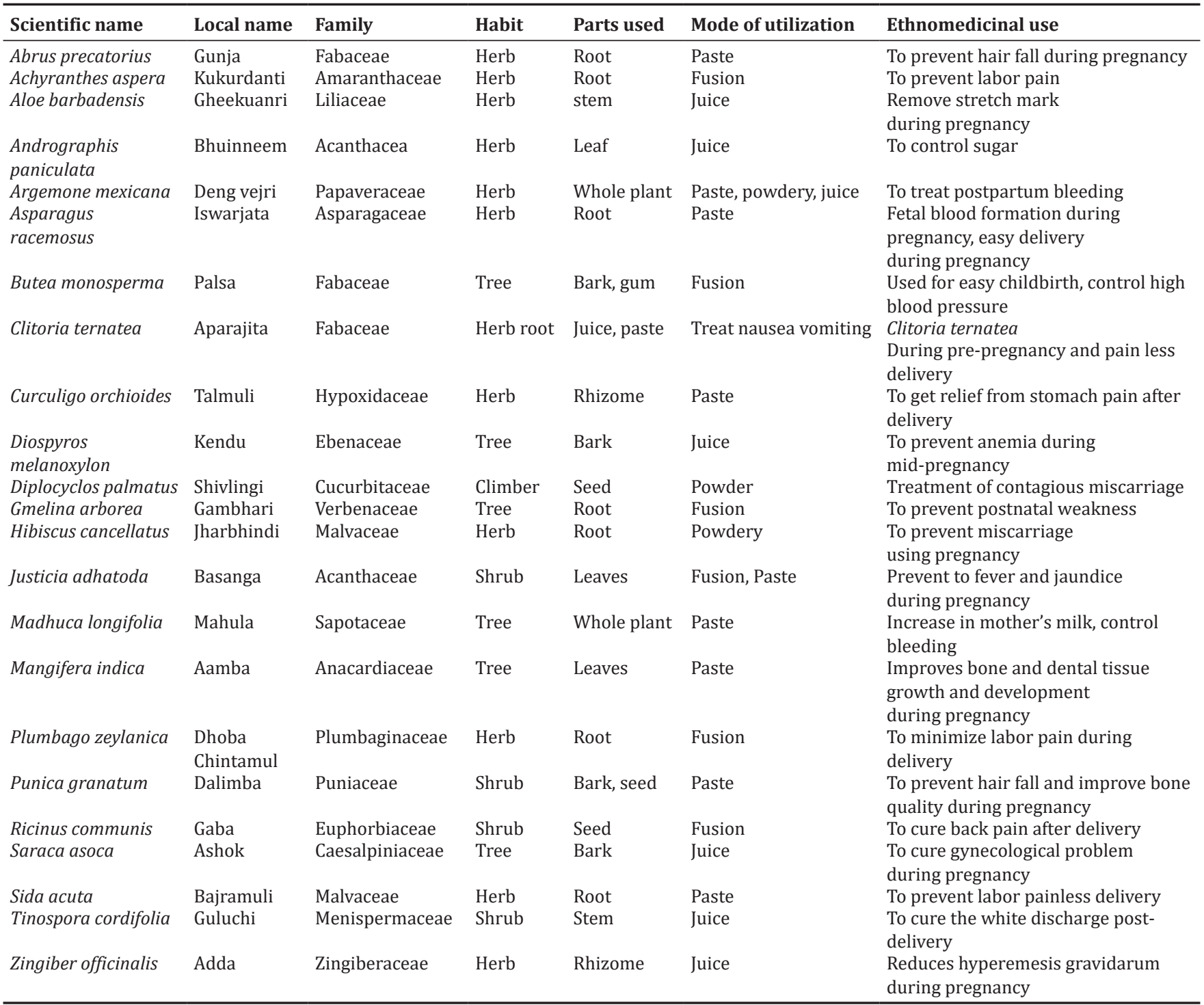

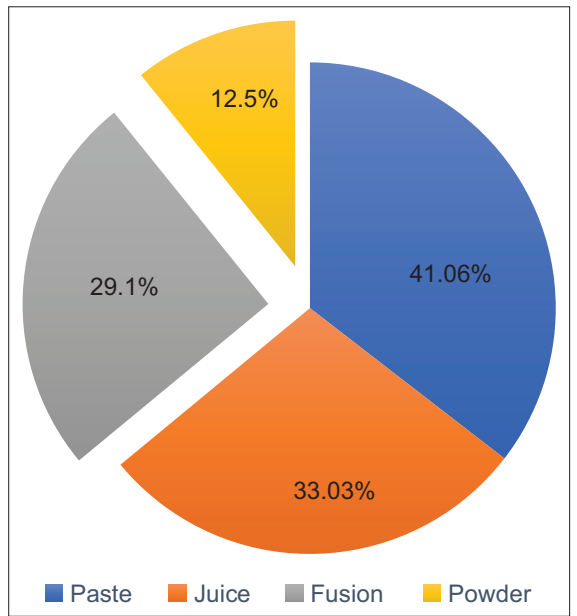

Fig. 4: Mode of utilization

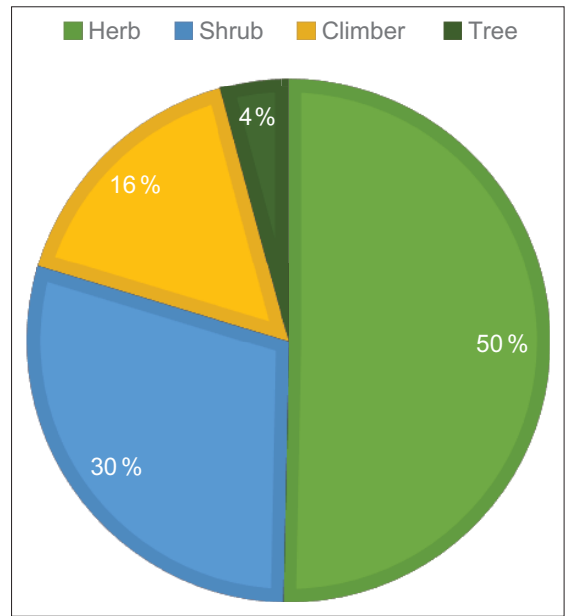

Fig. 5: Habit of plants 


\section{CONCLUSION}

Herbal medicines have several beneficial properties associated with pregnancy which is well illustrated by increasing milk production, decreasing nausea, easing labor pains, relief of morning sickness, or decreasing flatulence. However, in present times due to unwanted destruction of forest and grasslands have led to the extinct of some rare species of plants having high potential therapeutic values.

The ethnobotanical result documented in this study provides practical evidence about the use of medicinal plants among the inhabitants of Gandhamardan hills. Further, the findings revealed that the medicinal plants of the area are a major source of herbal drugs maternal care used among the rural communities. This survey can be used as baseline information for further scientific investigation and would pave a way for the discovery of a new drug.

\section{ACKNOWLEDGMENT}

The authors are grateful to the informants of the respective study site for their support and reciprocation during survey and field visits. The authors are thankful to the personnel of the forest department, Harishankar for their help with the field visits for the collection of floras. The help and cooperation of Centurion University of Technology and Management, Bhubaneswar, Odisha, for the fulfillment of the survey work is highly acknowledged.

\section{AUTHORS' CONTRIBUTIONS}

Kalpita Bhatta: Conceptualization and designing of the research work. Sonalika Das, Sulagana Mohaty, and Sheetiswapna Nayak: Survey, collection, and documentation of field data. All authors read, reviewed, and approved the final version of the manuscript.

\section{CONFLICTS OF INTEREST}

The authors declare that they have no conflicts of interest.

\section{AUTHORS' FUNDING}

Not applicable.

\section{REFERENCES}

1. Tengia-Kessy A, Msalale GC. Understanding forgotten exposures towards achieving sustainable development goal 3: A cross-sectional study on herbal medicine use during pregnancy or delivery in Tanzania. BMC Pregnancy Childbirth 2021;21:270.

2. Ahmed M, Im HB, Hwang JH, Han D. Disclosure of herbal medicine use to health care providers among pregnant women in Nepal: A cross-sectional study. Complement Med Ther 2020;20:339.

3. Beal MW. Women's use of complementary and alternative therapies in reproductive health care. J Nurse Midwifery 1998;43:224-34.

4. Ahmed SM, Nordeng H, Sundby J, Aragaw YA, de Boer HJ. The use of medicinal plants by pregnant women in Africa: A systematic review. J Ethnopharmacol 2018;224:297-313.

5. Patel PP, Trivedi ND. Simple, efficient and economic method for isolation and analysis of karanjin and pongamol from karanja seed oil and screening of antimicrobial potential. Int J Pharm Pharm Sci 2015;7:248-52.

6. Frawley J, Adams J, Steel A, Broom A, Gallois C, Sibbritt, D. Women's use and self-prescription of herbal medicine during pregnancy: An examination of 1,835 pregnant women. Womens Health Issues 2015;25:396-402.

7. Ghosh A. Herbal folk remedies of Bankuraand Medinipur districts, West Bengal. Ind J Trad Knowl 2003;2:393-6.

8. Behera, KK. Plants used for gynaecological disorders by tribal of Mayurbhanj district, Orissa, India. Ethnobot Leaf 2006;10:129-38.

9. Panigrahi G. Gandhamardhan Parbat, Orissa-a potential of important indigenous drugs. Bull Reg Res Lab Jammu 1963;1:11-6.

10. Bhatta K, Karmee P, Das KP. Ethno-medicinal studies on plant resources of Gandhamardan hill ranges, Odisha, India. Indian J Nat Sci 2020;10:26543-54

11. John LJ, Shantakumari N. Herbal medicines use during pregnancy: A review from the Middle East. Oman Med J 2015;30:229-36.

12. Saxena HO, Brahmam M. Vascular flora of Gandhamardan hills. J Econ Taxon Bot 1995;19:113-32.

13. Saxena HO, Brahmam M. The Flora of Orissa (1994-96). Vol. 1, 4. Bhubaneswar: Regional Research Laboratory and Forest Development Corporation of Orissa; 1994.

14. Haines HH. The Botany of Bihar and Orissa, 6 parts London (1921-25). Calcutta: Botanical Survey of India; 1921.

15. Jain SK, Rao RR. A Handbook of Field and Herbarium Methods. New Delhi: Today and Tomorrow s Printers and Publishers; 1977.

16. Vadnere GP, Usman MR, Lodhi S, Patil V. Phytochemical investigation and in vitro antimicrobial screening of Santalum album seeds extracts. Int J Pharm Pharm Sci 2017;9:117-24.

17. Basualdo I, Zardini EM, Ortiz M. Medicinal plants of Paraguay: Underground Organs, II. Econ Bot 1995;49:387-94.

18. Teklehaymanot T. An ethnobotanical survey of medicinal and edible plants of Yalo Woreda in Afar regional state, Ethiopia. J Ethnobiol Ethnomed 2017;13:40. 